\title{
Circuit
}

Musiques contemporaines

\section{Foi et création : même la mort se vit}

\section{Gilles Tremblay}

Volume 5, numéro 1, 1994

Gilles Tremblay : réflexions

URI : https://id.erudit.org/iderudit/902084ar

DOI : https://doi.org/10.7202/902084ar

Aller au sommaire du numéro

\section{Éditeur(s)}

Les Presses de l'Université de Montréal

ISSN

1183-1693 (imprimé)

1488-9692 (numérique)

Découvrir la revue

Citer cet article

Tremblay, G. (1994). Foi et création : même la mort se vit. Circuit, 5(1), 21-22. https://doi.org/10.7202/902084ar d'utilisation que vous pouvez consulter en ligne.

https://apropos.erudit.org/fr/usagers/politique-dutilisation/ 


\section{Même la mort se vit}

Paru dans Étapes, Bulletin de la Communauté chrétienne St-Albert, novembre 1980.

On n'a jamais tant écrit sur la mort, paraîtil, que depuis une dizaine d'années. Chaque mort est différente, vous diront ceux qui la côtoient fréquemment. Pour ma part, c'était la première fois que j'assistais un mourant: mon père. Or, je dois dire que malgré le tragique que reste la mort sous certains aspects, cela fut à la fois naturel, simple et merveilleux de communication silencieuse.

L'évocation de ces moments nous rendra peut-être un peu plus familière cette grande évacuée de notre civilisation actuelle, «notre sœur la mort» comme l'appelait saint François. L'immensité d'un ciel-plus-au-delà-où-ildevenait éclairait d'un bleu jamais vu son œil. Comme si en cette tragédie se manifestait en même temps la Bonté infinie et la souffrance abyssale du Christ, le frisson de l'abandon et la main du créateur-Père. Ce plus beau don durable et long d'un père à son fils venait pourtant d'un moribond, mon géniteur, comme si, en ce moment ultime où tout est de plus en plus essentiel, il était éclairé de l'intérieur par le regard même du Christ. Dire merci alors qu'il est vivant à ce regard de bonté, en tremblant...

Les circonstances manifestent parfois une certaine délicatesse, c'est ainsi que les aînés et les benjamins de deux générations se sont retrouvés chez lui à ce moment sans concertation, comme englobant symboliquement tous les absents.

Assumer tous les restes de soucis, s'assumer les uns les autres. Le lui dire tout haut, clairement, calmement. Son épouse l'embrasse avec la douceur de la tendresse. Spontanément, silencieusement aussi les mains se lient aux siennes, formant chaîne autour de lui de la droite à la gauche. La racine 
d'agonie est agon, combat. Celle de tendresse est la même que celle de tenir.

Dans la discrétion, gestes et délicatesse de l'amie infirmière, image d'accoucheuse. Ici s'applique bien dans son sens large l'expression de sagefemme. Le premier souffle est une inspiration, le dernier une expiration. Est-ce là l'origine de l'expression « rendre le souffle " (rendre l'âme) ?

Présence discrète et fervente de sa «petite sœur ». Silence. Prière. Puis, en ces vagues de respiration s'amenuisant, comme la vieille comparaison de la flamme qui vacille et s'éteint est juste! Silence.

Chant des oiseaux de mai dans les arbres. La fenêtre est ouverte. II nous a quittés.

Nous voici de ce côté de l'espace et du temps, avec notre alternante respiration, au seuil d'une dimension que nous ne connaissons pas encore mais qu'il commence à vivre. Et cela nous le savons - même si c'est encore de «manière obscure, comme dans un miroir - de façon suffisante pour nous remplir de joie et prononcer: Alleluia. 